\title{
Utility of Peripheral Blood Smear Examination in the Presence of Automated Haematology Analyser with Reference to Anaemia
}

\author{
Faiza Hafiz ${ }^{1}$, Akhtar Un Nisa Salaria², Kuldeep K. Koul ${ }^{3}$
}

1Department of Pathology, Government Medical College, Jammu, Jammu and Kashmir, India. ${ }^{2}$ Department of Pathology, Government Medical College, Jammu, Jammu and Kashmir, India. ${ }^{3}$ Department of Pathology, Government Medical College, Jammu, Jammu and Kashmir, India.

\section{ABSTRACT}

\section{BACKGROUND}

Anaemia is a global public health problem affecting both developing and developed countries. The morphological typing of anaemia is essential in clinical haematology for diagnostic and treatment purposes. Over the past few years, complete blood count (CBC) by automated haematology analysers and microscopic examination of peripheral smear have complemented each other to provide a comprehensive report on patient's blood sample. Despite this wealth of information, there are still morphological abnormalities that are critical in the differential diagnosis of anaemia and that can be determined only from a blood smear. The present study aims to evaluate the utility of peripheral blood smear examination in presence of automated haematology analyser with reference to anaemia after correlating type of anaemia based on RBC indices obtained from automated haematology analyser and on peripheral blood smear examination.

\section{METHODS}

This is a cross-sectional study conducted for a period of one year from November 1 , 2017 to October 31, 2018 on 100 anaemic patients of Government Medical College, Jammu and Associated Hospitals. EDTA anticoagulated samples were received in the laboratory and run on automated haematology analyser to obtain complete blood count including RBC indices. Simultaneously, well prepared and tongue shaped peripheral blood smears stained by Leishman's stain were studied in detail to observe the morphology of red blood cells.

\section{RESULTS}

On classifying anaemias into five major groups, it was seen that there were 40 patients of normocytic normochromic anaemia with normal RDW which correlated well with 40 patients of normocytic normochromic anaemia on peripheral blood film examination. Normocytic hypochromic anaemia with normal RDW was seen in 5 patients, whereas PBF showed normocytic hypochromic anaemia in 7 patients. 31 patients had microcytic hypochromic anaemia (with normal and raised RDW) as per analyser generated indices which correlated well with 29 patients of microcytic hypochromic anaemia on PBF. Both analyser and PBF showed that $10 \%$ patients had macrocytic anaemia. Dimorphic anaemia was seen in $14 \%$ patients on PBF. Out of 100 cases, $84 \%$ (84) of the cases showed concordance in the type of anaemia by analyser generated RBC indices and on peripheral blood film examination. Only $16 \%$ cases showed discordance in the type of anaemia which needed peripheral blood film examination for correct morphological classification of anaemia.

\section{CONCLUSIONS}

RBC parameters on analyser along with PBF findings are complimentary to each other rather than being the substitute. PBF is very important in certain clinical settings in patients with normocytic normochromic anaemia with raised RDW, pancytopenia and patients of fever who show normal or slightly abnormal parameters on analyser. Each haematology report has to be interpreted along with clinical presentation of the patient in order to arrive at diagnosis.

\section{KEY WORDS}

Anaemia, Automated Haematology Analyser, Peripheral Blood Film
Corresponding Author:

Dr. Faiza Hafiz,

H. No. 173, Sector 1 ,

Channi Himmat, Jammu-180015,

Jammu and Kashmir, India.

E-mail:faizaslmn@gmail.com

DOI: $10.14260 / \mathrm{jemds} / 2019 / 853$

Financial or Other Competing Interests: None.

How to Cite This Article:

Hafiz F, Salaria AUN, Koul KK. Utility of peripheral blood smear examination in the presence of automated haematology analyser with reference to anaemia. J. Evolution Med. Dent. Sci. 2019;8(52): 3941-3945, DOI

10.14260/jemds/2019/853

Submission 30-10-2019,

Peer Review 12-12-2019,

Acceptance 20-12-2019,

Published 30-12-2019. 


\section{BACKGROUND}

Anaemia is a global public health problem affecting both developing and developed countries with major consequences for human health as well as social and economic development. ${ }^{1}$ World Health Organisation (WHO) defines the lower limit of normal for haemoglobin concentration at sea level to be $12.0 \mathrm{~g} / \mathrm{dl}$ in women and 13.0 $\mathrm{g} / \mathrm{dl}$ in men. ${ }^{2}$ Anaemia is not a diagnosis itself, but it is a sign of underlying disease. Hence the evaluation of a patient with anaemia is directed at elucidating the causes for the patient's reduced number and morphological changes of red blood cells. An initial morphological classification of anaemia with integration of red blood cell indices and morphological characteristics is probably most useful. ${ }^{3}$

The morphological typing of anaemia is essential in clinical haematology for diagnostic and treatment purposes. Anaemia is diagnosed either by manual method i.e., peripheral blood smear examination or by automated haematology analyser. The microscopic examination of a peripheral blood smear provides a wealth of information to the clinician. Various forms of anaemia may actually be diagnosed from abnormal red cell morphology reported on a blood smear examination. ${ }^{4}$ Cell counters have penetrated medical laboratory services in a ubiquitous manner with increasing efficacy and decreasing cost all over the world. Over the past few years, complete blood count (CBC) by automated haematology analysers and microscopic examination of peripheral smear have complemented each other to provide a comprehensive report on patients' blood sample. 5

Automated analysers provide clinical laboratories with the capacity to efficiently handle a large volume of samples and provide superior accuracy and precision in quantitative blood cell measurements. 6 Despite this wealth of information, there are still morphological abnormalities that are critical in the differential diagnosis of anaemia and that can be determined only from a blood smear. ${ }^{7}$ The present study aims to evaluate the utility of peripheral blood smear examination in presence of automated haematology analyser with reference to anaemia after correlating type of anaemia based on RBC indices obtained from automated haematology analyser and on peripheral blood smear examination.

\section{METHODS}

It is a cross-sectional study conducted for a period of one year from November 1, 2017 to October 31, 2018 on 100 anaemic patients of Government Medical College, Jammu and Associated Hospitals who were referred to the haematology wing of the Department of Pathology by various clinical departments for routine Complete Blood Cell Counts. The Sample size was taken based on the convenience of the study. EDTA anticoagulated samples of the all anaemic patients with haemoglobin concentration less than $12 \mathrm{~g} / \mathrm{dl}$ in women and less than $13 \mathrm{~g} / \mathrm{dl}$ in men were received in the laboratory for morphological evaluation of anaemia. A detailed clinical history was taken from the anaemic patients and complete data of each patient was prepared. The samples were run on automated haematology analyser HORIBA Pentra DX Nexus which is a seven-part haematology analyser and smears were made simultaneously. The haematological investigations comprised of Complete Blood Count (CBC) on automated haematology analyser and Peripheral blood smear examination. Complete blood count (CBC) comprised of Haemoglobin estimation, Total erythrocyte count, Red cell indices comprising of mean corpuscular volume (MCV), mean corpuscular haemoglobin (MCH), mean corpuscular haemoglobin concentration (MCHC) and red cell distribution width (RDW). Well prepared and tongue shaped peripheral blood smears stained by Leishman's stain were studied in detail under low power (10x), high power (40x) and oil immersion lens (100x). The study was approved by Institute of Ethical Clearance and informed consent was obtained.

\section{Statistical Analysis}

Statistical analysis was performed using SPSS 10.0 for Windows, student version.

\section{RESULTS}

The age of the patients ranged from 21 to 86 years with majority of the patients (58\%) in the age group of $21-40$ years. Females constituted $55 \%$ of the total patients with female to male ratio of 1.22:1. Pallor was the most common clinical presentation seen in $45 \%$ of the patients. Majority of the patients (45\%) had mild degree of anaemia with haemoglobin levels more than $9 \mathrm{gm} / \mathrm{dl}$. Mean $\mathrm{Hb}$ in 100 patients of anaemia was $8.1 \mathrm{~g} / \mathrm{dl}$. RBC were divided into normocytes, microcytes and macrocytes by MCV generated by automated analyser. Normocytes (MCV 80-100 fL) were seen in majority (59\%) of the patients with mean MCV of 85.84 fl. Microcytic (MCV < $80 \mathrm{fL}$ ) and macrocytic (MCV > 100 fL) cases represented $31 \%$ and $10 \%$ of the patients respectively (Table 1 )

\begin{tabular}{|c|c|c|c|c|c|c|}
\hline RBC Size & MCV & $\begin{array}{c}\text { No. of } \\
\text { Patients }\end{array}$ & $\begin{array}{c}\text { \% } \\
\text { Age }\end{array}$ & $\begin{array}{c}\text { Min } \\
\text { MCV (fl) }\end{array}$ & $\begin{array}{c}\text { Max } \\
\text { MCV (fl) }\end{array}$ & $\begin{array}{c}\text { Mean } \\
\text { (SD) }\end{array}$ \\
\hline Normocytes & Normal & 59 & 59.0 & 80 & 100 & $85.84(6.08)$ \\
\hline Microcytes & Decreased & 31 & 31.0 & 52 & 79 & $67.70(7.27)$ \\
\hline Macrocytes & Increased & 10 & 10.0 & 102 & 122 & $110.9(6.22)$ \\
\hline Total & & 100 & 100 & & & \\
\hline \multicolumn{7}{|c|}{ Table 1. RBC Size as Measured by MCV on Analyser } \\
\hline \multicolumn{7}{|c|}{}
\end{tabular}

Majority of the patients (61\%) patients had normochromia on the basis of MCHC obtained from the analyser and 39\% patients showed hypochromia (Table 2).

\begin{tabular}{|c|c|c|c|c|c|}
\hline Chromia & $\begin{array}{c}\text { No. of } \\
\text { Patients }\end{array}$ & $\begin{array}{c}\text { \% } \\
\text { Age }\end{array}$ & $\begin{array}{c}\text { Min MCHC } \\
\text { (g/dl) }\end{array}$ & $\begin{array}{c}\text { Max MCHC } \\
\text { (g/dl) }\end{array}$ & $\begin{array}{c}\text { Mean } \\
\text { MCHC(SD) }\end{array}$ \\
\hline Normochromia & 61 & 61.0 & 32.0 & 36.0 & $35.22(0.87)$ \\
\hline Hypochromia & 39 & 39.0 & 18.5 & 31.8 & $30.39(2.21)$ \\
\hline Total & 100 & 100 & & & \\
\hline \multicolumn{6}{|c|}{ Table 2. Chromia as Measured by MCHC on Analyser }
\end{tabular}

\begin{tabular}{|c|c|c|c|c|c|c|}
\hline Anisocytosis & RDW & $\begin{array}{c}\text { No. of } \\
\text { Patients }\end{array}$ & $\begin{array}{c}\text { \% } \\
\text { Age }\end{array}$ & $\begin{array}{c}\text { Min } \\
\text { RDW } \\
(\%)\end{array}$ & $\begin{array}{c}\text { Max } \\
\text { RDW } \\
(\%)\end{array}$ & $\begin{array}{c}\text { Mean } \\
\text { RDW } \\
\text { (SD) }\end{array}$ \\
\hline Absent & Normal & 59 & 59.0 & 11.60 & 14.60 & $13.63(.80)$ \\
\hline Present & Raised & 41 & 41.0 & 15.50 & 33.0 & $22.21(4.43)$ \\
\hline Total & & 100 & 100 & & & \\
\hline \multicolumn{7}{|c|}{ Table 3. Anisocytosis as Measured by the RDW on Analyser } \\
\hline
\end{tabular}


On PBF, the results were comparable with that of analyser with normochromic and hypochromic cases representing $54 \%$ and $46 \%$ of the patients respectively. Anisocytosis on analyser was detected in $49 \%$ cases. The RDW ranged from $11.6 \%$ to $33 \%$ with mean of 19.3 (Table 3). Even on peripheral blood film examination, anisocytosis was present in $49 \%$ cases which is comparable to the findings on analyser. Anisocytosis grade $1+, 2+, 3+$ and $4+$ was detected among $13 \%, 24 \%, 11 \%$ and $1 \%$ cases respectively.

Majority of the patients (40\%) had normocytic normochromic anaemia with normal RDW on the basis of analyser generated RBC indices followed by microcytic hypochromic anaemia seen in $31 \%$ patients. On PBF also majority of the patients (40\%) showed normocytic normochromic anaemia followed by microcytic hypochromic anaemia seen in $29 \%$ cases (Table 4 ).

\begin{tabular}{|c|c|c|c|c|}
\hline \multirow{2}{*}{$\begin{array}{l}\text { Morphological } \\
\text { Type of Anaemia }\end{array}$} & \multicolumn{3}{|c|}{ RBC Indices with RDW (Analyser) } & \multirow[b]{2}{*}{ PBF } \\
\hline & $\begin{array}{c}\text { With Normal } \\
\text { RDW }\end{array}$ & $\begin{array}{c}\text { With Raised } \\
\text { RDW }\end{array}$ & $\begin{array}{c}\text { Total No. } \\
\text { of Patients }\end{array}$ & \\
\hline Normocytic Normochromic & 40 & 11 & 51 & 40 \\
\hline Normocytic Hypochromic & 5 & 3 & 8 & 7 \\
\hline Microcytic Hypochromic & 7 & 24 & 31 & 29 \\
\hline Macrocytic anaemia & 7 & 3 & 10 & 10 \\
\hline Dimorphic anaemia & \multirow{2}{*}{\multicolumn{2}{|c|}{100}} & & 14 \\
\hline Total & & & 100 & 100 \\
\hline \multicolumn{5}{|c|}{$\begin{array}{l}\text { Table 4. Morphological Type of Anaemia on the Basis of Analyser } \\
\text { Generated RBC Indices and on PBF Examination }\end{array}$} \\
\hline
\end{tabular}

On correlating the type of anaemia by analyser and PBF, normocytic normochromic anaemia with normal RDW was seen in 40 patients which was similar to the findings on PBF. Normocytic hypochromic anaemia with normal RDW was seen in 5 patients, whereas PBF showed normocytic hypochromic anaemia in 7 patients. 31 patients had microcytic hypochromic anaemia (With normal and raised RDW) as per analyser generated indices which correlated well with 29 patients of microcytic hypochromic anaemia on PBF. Both analyser and PBF showed 10\% patients with macrocytic anaemia. Dimorphic anaemia which comprised of two population of RBCs (normocytes with microcytes and microcytes with normocytes) were seen in $14 \%$ patients on PBF (Table 5).

\begin{tabular}{|c|c|}
\hline $\begin{array}{l}\text { Type of Anaemia on Analyser } \\
\text { (No. of Patients) }\end{array}$ & $\begin{array}{l}\text { Type of Anaemia on PBF } \\
\text { (No. of Patients) }\end{array}$ \\
\hline $\begin{array}{c}\text { Normocytic Normochromic anaemia with } \\
\text { normal RDW }(40)\end{array}$ & Normocytic Normochromic anaemia(40) \\
\hline $\begin{array}{c}\text { Normocytic Hypochromic anaemia with } \\
\text { normal RDW(5) }\end{array}$ & Normocytic Hypochromic anaemia(7) \\
\hline Microcytic Hypochromic anaemia(31) & Microcytic Hypochromic anaemia(29) \\
\hline Macrocytic anaemia(10) & Macrocytic anaemia(10) \\
\hline Normocytic anaemia with raised RDW(14) & Dimorphic anaemia(14) \\
\hline
\end{tabular}

In our study, out of 100 cases, 84\% (84) of the cases showed concordance in the type of anaemia by analyser generated RBC indices and on peripheral blood film examination. Only $16 \%$ cases showed discordance in the type of anaemia which needed peripheral blood film examination for correct morphological classification of anaemia. Kappa statistics for agreement between the two methods (automated and manual) was equal 0.545 (moderate agreements), $p$ value $=0.0001$ that is the agreement between the two methods was statistically significant. Some parameters which were assessed manually did not have a corresponding parameter on automated counts. They included tear drop cells, pencil cells, sickle cells, hyper segmented neutrophils, red blood cells containing Cabot ring, Howell Jolly body and basophilic stippling.

\section{DISCUSSION}

This study was undertaken to bring out the utility of peripheral blood smear examination in presence of automated haematology analyser with reference to anaemia. We studied the morphological type of anaemia on the basis of automated haematology analyser generated RBC indices (MCV, MCH, MCHC and RDW) and on peripheral blood smear examination. In our study, the result of data analysis obtained showed a predominance of females (55\%) amongst 100 anaemic patients with female to male ratio of 1.22:1. Majority of the patients (58\%) belonged to the age group of 21-40 years which is comparable with that reported in literature. ${ }^{8,9,10}$ In our study, pallor was the most common clinical presentation seen in $45 \%$ of the patients. Similar results were obtained in a study conducted by Chandurkar $\mathrm{M}$ \& Pendalya S.11 In our study, the mean value of MCV (fl), $\mathrm{MCH}$ (pg) and MCHC (g/dl) in 100 patients of anaemia was $82.72 \mathrm{fl}$, $28.54 \mathrm{pg}$ and $33.33 \mathrm{~g} / \mathrm{dl}$. Sandhya V \& Rashmi GS12 also reported mean MCV, MCH and MCHC of $81.09 \mathrm{fl}, 25.2 \mathrm{pg}$ and $31.11 \mathrm{~g} / \mathrm{dl}$ respectively. Normocytes (MCV 80-100fL) were seen in majority (59\%) of the patients with mean MCV of 85.84 fl. Microcytic (MCV < $80 \mathrm{fL}$ ) and macrocytic (MCV > 100 fL) cases represented $31 \%$ and $10 \%$ of the patients respectively which is comparable with that reported in literature. Normochromia was seen in $61 \%$ patients and hypochromia in 39\% patients on the basis of MCHC obtained from the analyser. Similar results were obtained by in a study conducted by Singla S et al. 5 On PBF examination also the results were comparable with normochromic and hypochromic cases representing $54 \%$ and $46 \%$ of the patients respectively. Kerdany $\mathrm{TA}$ et $\mathrm{al}^{13}$ also reported normochromic cases $61 \%$ and hypochromic cases $39 \%$ of the sample on analyser and $66 \%$ and $34 \%$ on PBF respectively. The RDW in our study ranged from $11.6 \%$ to $33 \%$ with the mean value of 17.15 . Anisocytosis on analyser was detected in $41 \%$ cases. The RDW in the study conducted by Sandhya V \& Rashmi GS ${ }^{12}$ ranged from $12.4 \%$ to $39.2 \%$ with mean of $19.3 \%$. Even on PBF, anisocytosis was present in $49 \%$ cases which is comparable to the findings on analyser. Anisocytosis grade $1+, 2+, 3+$ and $4+$ was detected among $13 \%, 24 \%, 11 \%$ and $1 \%$ cases respectively. Kerdany TA et al ${ }^{13}$ also reported similar results.

Majority of the patients (40\%) showed normocytic normochromic anaemia with normal RDW on the basis of analyser generated RBC indices followed by microcytic hypochromic anaemia seen in $31 \%$ patients. On PBF also majority of the patients $(40 \%)$ showed normocytic normochromic anaemia followed by microcytic hypochromic anaemia seen in $29 \%$ cases. This finding was similar to the study by Kaur $\mathrm{H}$ et al ${ }^{14}$ in which normocytic normochromic anaemia was the predominant type seen in $56 \%$ cases. 
After correlating the type of anaemia obtained from analyser generated RBC indices and on PBF examination, it was seen that out of 100 cases, $84 \%$ showed concordance in the type of anaemia by analyser generated RBC indices and on peripheral blood film examination. These were normocytic anaemia with normal RDW, microcytic hypochromic anaemia and macrocytic anaemias. Out of these 16 patients, two patients were wrongly categorised under microcytic hypochromic anaemia on analyser as they showed a normocytic hypochromic picture on PBF. This difference was because of the cut off value for MCV in our study was $80 \mathrm{fl}$ and these two patients had MCV values of 77 and $78 \mathrm{fl}$ respectively which is close to our cut off value. 14 patients who were diagnosed as normocytic anaemia with raised RDW by analyser showed dimorphic anaemia on PBF examination. Majority of the patients with microcytic hypochromic red blood cells with raised RDW showed additional morphological features indicative of iron deficiency anaemia. However, 7 patients of microcytic hypochromic anaemia with normal RDW did not show these additional RBC features (Anaemia of chronic disorders). The dimorphic picture was seen in patients with severe anaemia with $\mathrm{Hb}$ levels less than $6 \mathrm{~g} / \mathrm{dl}$ who had received multiple blood transfusions. The dimorphic blood picture comprising of dual population of microcytic and normocytic or microcytic and macrocytic red cells or a admixture of small, normal and large cells of different sizes and forms can mislead the diagnosis if we rely on automated values alone. The probable reasons as discussed by Aslina et $\mathrm{al}^{15}$ are that MCV is an average value and doesn't reflect the presence of different red cell population. Therefore, in all patients with normal range MCV and raised RDW peripheral smear examination is a must for identifying early red blood cell changes. Majority of the cases with microcytic hypochromic anaemia showed high RDW thus confirming that RDW is a very sensitive indicator of anisocytosis. RDW also shows a better correlation as an indicator of anisocytosis when the MCV is in the low normal range and anisocytosis is difficult to detect like in cases of developing iron deficiency. In nutritional deficiencies like iron, folate or vitamin B12 there is increase in red cell heterogeneity producing more abnormal cells in peripheral blood. ${ }^{5}$ On applying Kappa statistics for agreement between the two methods (automated and manual), it was equal to 0.545 (moderate agreements), $\mathrm{p}$ value $=0.0001$ that is the agreement between the two methods was statistically significantS. Similar result was obtained in a study by Sandhya V \& Rashmi GS. ${ }^{12}$

Hence our study showed that PBF provided additional information in only $16 \%$ cases of anaemia. This was in concordance with the study conducted by Singal $\mathrm{S}$ et al ${ }^{16}$ which showed that PBS examination provide additional information only in $11.4 \%$ cases of anaemia. Almost similar result was obtained by Froom $\mathrm{P}$ et al ${ }^{17}$ as PBF provided additional information in $13.9 \%$ cases. Novis DS et al 18 reported that PBS examination provide additional information in $6.4 \%$ cases of anaemia.

Besides dimorphic anaemia, there are other findings which can be identified on PBF examination. Some parameters which were assessed manually did not have a corresponding parameter on automated counts. They included tear drop cells, pencil cells, sickle cells, hyper segmented neutrophils, red blood cells containing Cabot ring,
Howell Jolly body and basophilic stippling. Detailed RBC morphology including RBC inclusions, NRBC, haemoparasite along with any abnormal/atypical/leukemic cell was possible only on a peripheral blood film examination. The benefit of manual scan is the ability to identify clinically significant cell types (pencil cells, tear drop cells, burr cells, schistocytes, target cells, sickle cells, blast cells) that are not quantifiable by instruments, but that produce flags on the automated results. ${ }^{19,20,21}$

The automated haematology analyser readings are as reliable as the standard manual method, even though the manual scan of peripheral smear provides additional diagnostic information. Hence, PBS examination even today cannot be totally replaced by automated haematology analysers as they provide so much additional information which cannot be summarized completely by the mere numerical calculations of an automated analyser but the present generation of automated haematology analysers are well on par and provide accurate morphological typing of anaemia in cases of Microcytic Hypochromic Anaemia, Macrocytic Anaemia and Normocytic Normochromic Anaemia with normal RDW thus reducing the workload and thereby increasing the efficiency of a laboratory. However, in cases of Normocytic Normochromic Anaemia with raised RDW, PBS examination provides valuable information and is absolutely necessary for morphological typing of anaemia. Bain $\mathrm{BJ}^{7}$ in her review on the place of peripheral blood smear examination in the age of automation in 2005 stated that even in the age of molecular analysis, the blood smear remains an important diagnostic tool and sophisticated modern investigations of haematologic disorders should be interpreted in the light of peripheral blood features as well as the clinical context.

\section{CONCLUSIONS}

Red cell parameters from haematology analyser are very useful for the initial assessment of anaemia in vast majority of patients. RDW remains a vital parameter in deciding in those anaemia cases in which other red cell parameters are inconclusive or within the normal range. In certain situations where the red cell parameters on haematology analyser are inconclusive, there interpretation should be done after detailed PBF examination to determine the underlying type of anaemia and/or underlying condition. Detailed PBF examination still remains the cornerstone as it can correlate effectively with RBC parameters generated on analyser and at the same time a lot of other additional information regarding the $\mathrm{RBC}, \mathrm{WBC}$ and platelets etc. which is possible only from a PBF examination that can indicate the possible underlying disorder. RBC parameters on analyser along with PBF findings are complimentary to each other rather than being the substitute. PBF is very important in certain clinical settings in patients with normocytic normochromic anaemia with raised RDW, pancytopenia and patients of fever who show normal or slightly abnormal parameters on analyser. Each haematology report has to be interpreted along with clinical presentation of the patient in order to arrive at the diagnosis. 


\section{REFERENCES}

[1] De Benoist B, McLean E, Egli I, et al. Worldwide prevalence of anaemia 1993-2005. WHO global database on anaemia. Geneva: WHO 2008.

http://www.who.int/nutrition/publications/micronutri ents/anaemia_iron_deficiency/9789241596657/en/

[2] Glader B. Anaemia: general considerations. In: Greer JP, Rodgers GM, Paraskevas F, et al, eds. Wintrobe's clinical haematology. $13^{\text {th }}$ edn. Philadelphia: Wolters Kluwer Company 2014:587-93.

[3] Farah E, Mehwish A, Nafisa HA. Comparative study in the diagnosis of anaemia by Sysmex KX-21N haematology analyser with peripheral blood smear. Int J Endor Health Sci Res 2013;1(2):89-92.

[4] Jones KW. Evaluation of cell morphology and introduction to platelet and white blood cell morphology. In: Harmening D, ed. Clinical haematology and fundamentals of haemostasis. Philadelphia: F.A. Davis Company 2009:93-116.

[5] Singla S, Bedi S, Joshi K. Comparative study of anaemia cases based on peripheral blood smears and cell counter generated red cell indices. Int Med J 2017;4(1):44-8.

[6] Yu H, Ok CY, Hesse A, et al. Evaluation of an automated digital imaging system, next slide digital review network, for examination of peripheral blood smears. Arch Pathol Lab Med 2012;136(6):660-7.

[7] Bain BJ. Diagnosis from the blood smear. N Engl J Med 2005;353(5):498-507.

[8] Kadgi NV. Utility of automated RBC parameters in evaluation of anaemia. Int J Healthcare Biomed Res 2015;3(3):170-81.

[9] Swaroop Raj BV, Sunita BS, Tewari V, et al. Is peripheral blood smear examination an obsolete art? International Journal of Recent Scientific Research 2015;6(3):3059-62.

[10] Mishra P, Ahluwalia SK, Garg PK, et al. The prevalence of anaemia among reproductive age group (15-45yrs) women in a PHC of rural field practice area of MM Medical College, Ambala. India J Women's Health Care 2012;1:3.
[11] Chandurkar M, Pendalya S. Clinical profile of patients presenting with anaemia in a tertiary care rural hospital of Western Maharashtra. Int J Clin Biomed Res 2017;3(4S):74-7.

[12] Sandhya V, Rashmi GSB. Correlation of peripheral smear with RBC indices and RBC histograms in the diagnosis of anaemia. Indian Journal of Pathology and Oncology 2017;4(2):242-6.

[13] El Kerdany TA, El Ela SA, Aziz JBS. Study of automated red blood cells parameters in correlation with routine rbcs morphology by smear review. The Egyptian Journal of Hospital Medicine 2017;68(3):1358-63.

[14] Kaur H, Piplani S, Madan M. Prevalence of anaemia and micronutrient deficiency in elderly. International Journal of Medical and Dental Science 2014;3(1):296-302.

[15] Aslinia F, Mazza JJ, Yale SH. Megaloblastic anaemia and other causes of macrocytosis. Clin Med Res 2006;4(3):236-41.

[16] Singhal S, Verma N, Rathi M, et al. Can peripheral blood smear examination be totally replaced by automated haematology analyser - with special reference to anaemia? Int J Res Med Sci 2016;4(10):4563-6.

[17] Froom $P$, Havis $R$, Barak $M$. The rate of manual peripheral blood smear reviews in outpatients. Clin Chem Lab Med 2009;47(11):1401-5.

[18] Novis DA, Walsh M, Wilkinson D, et al. Laboratory productivity and the rate of manual peripheral blood smear review: a College of American Pathologists QProbes study of 95,141 complete blood count determinations performed in 263 institutions. Arch Pathol Lab Med 2006;130(5):596-601.

[19] Cornbleet J, Fernandes BJ, Miers M. Streamline your automated haematology laboratory. Roundtable discussion. MLO Med Lab Obs 1997;29(2):43-6.

[20] Dutcher TF. Automated differentials: a strategy. Blood Cells 1985;11(1):49-59.

[21] Gulati G, Kocher W, Schwarting R, et al. An assessment of the Coulter Gen-S automated flagging system. Lab Med 2001;32(6):310-7. 